Research Article

\section{Rehabilitation of hearing by cochlear implantation}

\section{Abdelaziz Raji*, Houda Mounji, Youssef Rochdi, Hassan Nouri and Mehdi Elfakiri}

Department of Otolaryngology, Head and Neck Surgery, University Hospital Mohammed VI Marrakech, Morocco

\section{Abstract}

Background: Cochlear implants $(\mathrm{Cl})$ are nowadays a widely accepted treatment for sensorineural hearing loss SNHL.

Aim: This study aimed to describe the epidemiological characteristics and the surgical approach and to evaluate the outcomes of our experience in cochlear implantation.

Setting: Department of Otolaryngology-Head and Neck Surgery of University Hospital Mohammed VI Marrakech Morocco.

Methods: A retrospective chart review was conducted on 113 patients with severe to profound hearing loss who underwent a cochlear implantation between 2007-2018.

Results: There were 65 females and 48 males with severe to profound bilateral deafness, of whom 103 had prelingual deafness. The mean age of pediatric cochlear implantation was 5.25 years. Implantation was unilateral in all patients. The procedure was followed by regular adjustments and speech therapy. The evaluation was carried out by the same team each month during the first 6 months, then every 6 months. The average duration of follow-up was 37.54 months. All patients benefited from their implants with inter individual variability.

The good results were correlated with early implantation, significant parental investment and a steady follow-up of speech therapy.

Conclusion: Cochlear implantation has revolutionized the management of severe to profound deafness. It is a safe and effective technique when it is aimed at correctly selected populations.

\section{More Information}

*Address for Correspondence: Abdelaziz Raji, Professor, Department of Otolaryngology, Head and Neck Surgery, University Hospital Mohammed VI Marrakech, Morocco, Tel: 00212 673083981; +2126613234 77; Email: raji.abdelaziz@gmail.com

Submitted: 03 May 2019

Approved: 23 July 2019

Published: 24 July 2019

How to cite this article: Raji A, Mounji $\mathrm{H}$, Rochdi $\mathrm{Y}$, Nouri $\mathrm{H}$, Elfakiri M. Rehabilitation of hearing by cochlear implantation. J Nov Physiother Rehabil. 2019; 3: 082-086.

DOI: 10.29328/journal.jnpr.1001028

Copyright: @ 2019 Raji A, et al. This is an open access article distributed under the Creative Commons Attribution License, which permits unrestricted use, distribution, and reproduction in any medium, provided the original work is properly cited

Keywords: Hearing loss; Cochlear implant; Rehabilitation; Speech

\section{Check for updates}

OPEN ACCESS

\section{Introduction}

A cochlear implant (CI) is a surgically implanted electronic device that transmits sounds directly to the auditory nerve through electrical stimulation of the cochlea. It has become the standard of care for severe or profound losses in hearing and indeed has produced the first substantial restoration of a lost or absent human sense using a medical intervention. It has proven to be a useful treatment option for individuals with severe-to-profound hearing loss by providing improved access to one's surrounding auditory environment. Both postlingually deafened adults and prelingually deafened children can benefit from a CI [1]. The goal of the present study is to describe the epidemiological characteristics, the surgical approach and the outcomes of our experience regarding the aural rehabilitation by cochlear implantation.

\section{Materials and Methods}

We completed a retrospective study of children with profound hearing loss implanted in our department between 2007 and 2018. The data were collected from patients records and from the speech-language evaluation forms completed in the presence of surgeons, speech therapists and parents of children.The patients were assessed regularly during the first 1-3 months and every 6 months after cochlear implantation. Communication abilities of the children are studied, on base of the APCEI-score. It evaluates five components of the language: cochlear implant acceptance, perceptive language performance, comprehension of the oral orders, expressive language and speech intelligibility. Scores for each item range from 0 to 5 . The highest possible score on the APCEI-scale is 25 (Figure 1).

\section{Results}

\section{Epidemiological data}

A total of 113 children with profound bilateral hearing loss implanted from 2007 to 2018 were included in the study. 
Among all patients 103 had prelingual deafness. The implant in children progressively increased through the considered time interval (Figure 2).

The average age of implantation was 5,25 years old, with a minimum of 18 months old and a maximum of 16 years old. The majority of patients were female $(57.5 \%)$ ).In the majority of cases (89.5\%) the CI was performed before 5 years old. Several causes of deafness were also identified (Table 1). However, the majority of the cases were unknown.

\section{Pre-implant assessment}

All patients benefited from a pre-implant assessment (clinical, audiological, radiological, orthophonic and psychological evaluation). There was no contraindication for cochlear implantation.

\begin{tabular}{|c|c|c|}
\hline Aetiology & Number & $\%$ \\
\hline $\begin{array}{l}\text { Unknown } \\
\text { Congenital } \\
\text { progressive }\end{array}$ & $\begin{array}{c}97 \\
90 \\
7\end{array}$ & $\begin{array}{c}85,8 \\
79,6 \\
5,3\end{array}$ \\
\hline $\begin{array}{c}\text { Syndromic } \\
\text { Waardenburg } \\
\text { Albinism-deafness } \\
\text { Susac }\end{array}$ & $\begin{array}{l}7 \\
5 \\
1 \\
1\end{array}$ & $\begin{array}{c}6,1 \\
4,4 \\
0,08 \\
0,08\end{array}$ \\
\hline $\begin{array}{c}\text { Acquired } \\
\text { Perinatal hypoxia } \\
\text { Meningitis } \\
\text { Rubella infection } \\
\text { Others }\end{array}$ & $\begin{array}{l}9 \\
4 \\
2 \\
1 \\
2\end{array}$ & $\begin{array}{c}7,9 \\
3,5 \\
1,7 \\
0,08 \\
1,7\end{array}$ \\
\hline
\end{tabular}

\begin{tabular}{|c|c|c|c|c|c|c|}
\hline $\begin{array}{l}\text { APCEI } \\
\text { score }\end{array}$ & 0 & 1 & 2 & 3 & 4 & 5 \\
\hline $\begin{array}{c}\text { Acceptation } \\
\text { (wearing of the } \\
\text { cochlear implant) }\end{array}$ & Rejection & Opposed & $\begin{array}{l}\text { Not obiligated, } \\
\text { intermititent, } \\
\text { all dat } \\
\text { all lang }\end{array}$ & 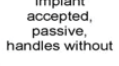 & $\begin{array}{l}\begin{array}{l}\text { Implant asked, } \\
\text { batteress? } \\
\text { active use }\end{array}\end{array}$ & 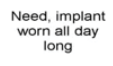 \\
\hline $\begin{array}{l}\text { Perception } \\
\text { (attention, } \\
\text { threshold, } \\
\text { itscrimination of } \\
\text { the sounds) }\end{array}$ & Anacousia & 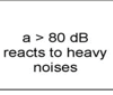 & $\begin{array}{l}a=80-600 d B \\
\text { high voicess } \\
\text { some noises }\end{array}$ & 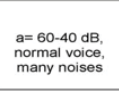 & $\begin{array}{l}=40=40.20 \mathrm{~dB}, \\
\text { feeble voice, }\end{array}$ & 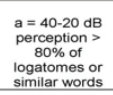 \\
\hline $\begin{array}{l}\text { Comprehension } \\
\text { (discriminationon of } \\
\text { the words, } \\
\text { meaning of the } \\
\text { message) }\end{array}$ & Nothing & $\begin{array}{l}\text { Autidory } \\
\text { conscience }\end{array}$ & $\begin{array}{l}\text { Locates } \\
\text { speecch/noises, } \\
\text { identifies some } \\
\text { tamiliar noises, } \\
\text { knows his name }\end{array}$ & 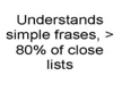 & $\begin{array}{l}\text { Identifies frases, } \\
\text { undorstands } \\
\text { Po\% of open } \\
\text { lists, oses the } \\
\text { phone with } \\
\text { relatives } \\
\text { relates }\end{array}$ & 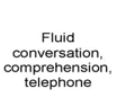 \\
\hline $\begin{array}{l}\text { Oral exprossison } \\
\text { (vole use } \\
\text { syntax), }\end{array}$ & Mutism & $\begin{array}{l}\text { produces } \\
\text { sounds } \\
\text { intentinout } \\
\text { communication }\end{array}$ & $\begin{array}{l}\text { Association of } \\
\text { mann worrds. } \\
\text { simpletrases. } \\
\text { bad syntax }\end{array}$ & $\begin{array}{l}\text { Association de } \\
\text { plusieurs mots. } \\
\text { phrasest } \\
\text { simples. } \\
\text { mavuaise } \\
\text { syntaxe }\end{array}$ & $\begin{array}{l}\text { Good syntax, no } \\
\text { spontaneity or } \\
\text { fluidity }\end{array}$ & 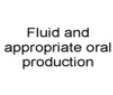 \\
\hline $\begin{array}{l}\text { Speecech } \\
\text { Inteiligibility }\end{array}$ & Mutism & Non intelligible & $\begin{array}{c}\text { Some intelligible } \\
\text { words }\end{array}$ & $\begin{array}{l}\text { Understood by } \\
\text { parents or } \\
\text { professionals }\end{array}$ & $\begin{array}{l}\text { Understood by } \\
\text { profossionals }\end{array}$ & 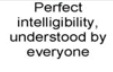 \\
\hline
\end{tabular}

Figure 1: The APCEI-scale evaluates five components of the language: cochlear implant acceptance, perceptive language performance, comprehension of the oral orders, expressive language and speech intelligibility [18].

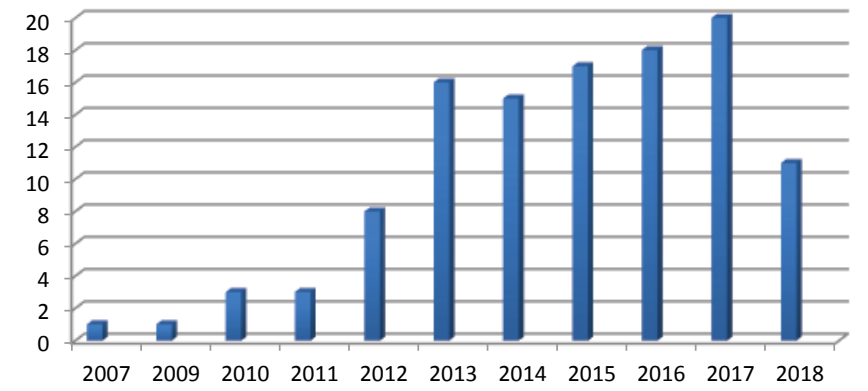

Figure 2: Number of cochlear implant per year.
Otitis media with effusion (OME) was identified in 8 patients, treated before surgery (medical treatment in 4 cases, adenoidectomy in 1 case, adenoidectomy +ear tube ventilation in 3 cases). The hearing aids were used in 10 patients. The associated comorbidities in the patients were: heart disease ( 2 cases), unilateral blindness ( 1 case) paresis of the left hemibody ( 1 case) and anemia (1 case). A unilateral complex cochlear malformation was identified by imaging in two patients implanted on the versus side.

\section{Surgical approach}

All Patients were preoperatively vaccinated (pneumococcal vaccination) for meningitis prophylaxis. Implantation was unilaterally in all cases: 100 cases in the right ear and 13 cases in the left one. Surgical revision with reimplantation was performed in 3 cases due to device failure. One of the cases had the first implantation in our department.

The surgery was performed under general anesthesia with monitoring of the facial nerve. A mastoidectomy with facial recess approach was performed in all cases to access the round window for placing the electrode (Figure 3). In all our patients the electrode arrays were fully inserted into the scala tympani except for two cases: reimplantation (1case) and post meningitis hearing loss (1case). Impedance testing and neural response telemetry (NRT) were performed to test the integrity of the device. There was no peroperative complication.

\section{Follow-up}

The duration of hospitalization was 48 hours in average. $\mathrm{X}$-ray Sternvers view was performed systematically, it showed the correct location of the cochlear implant in all patients. No post implantation complication was noted.

The "initial stimulation" and device programming, were conducted after 4-6 weeks of recovery with regular speech therapy at an average of 2 sessions per week. The adjustments were regular and modified afterwards according to the evolution in speech therapy, schematically at $1,2,3,6,9,12$, 18,24 months then yearly.

\section{Evaluation of communications abilities after cochlear implantation}

The speech-language assessment by the APCEI scale was

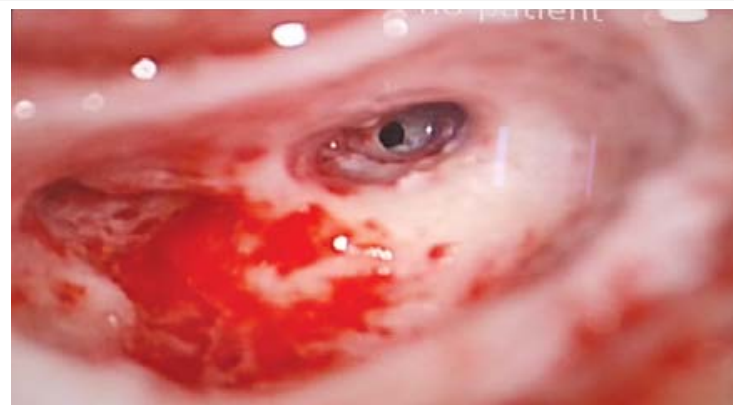

Figure 3: Peroperative image showing the round window. 
conducted in pre-implantation and during follow-up. All patients had a score of 0 prior to cochlear implantation in all areas of the used scale. The evaluation was done monthly during the first 6 months, and there after every 6 months. Figure 4 illustrates the evolution of the APCEI scale during the last control and according to the length of cochlear implant use.

All patients in our experience benefited from their implants with a mean follow-up of 37.54 months. The communications abilities improved during the period of use of the cochlear implant. Results showed high interindividual variability (age of implantation, the duration of implant use, motivation, rhythm of speech therapy). Figure 5 represents the average APCEI score of children with prelingual deafness according to the age of implantation. Good results were found to be correlated with early implantation.

Children with a significant parental investment and good follow-up of speech therapy had the best results compared to children with low or moderate follow-up Figure 6.

The oral environment had a positive influence on the results unlike the signed communication Figure7.

Regarding our global results, all patients accepted the use of the cochlear implant with an acquisition of sound alertness from the first months. The words recognition started from 1 year of use, and the possibility to understand a conversation from the 3rd year. The cochlear implant has allowed a schooling rate of $80,95 \%$ in our population with a failure rate of $1,85 \%$.

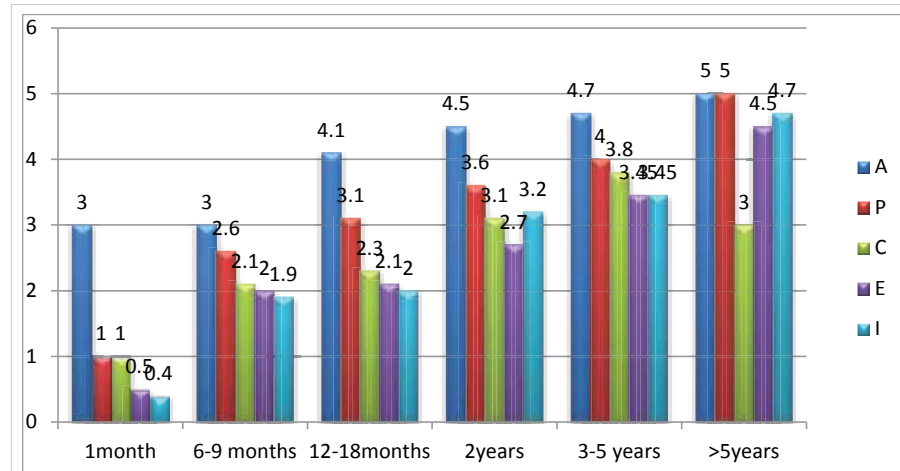

Figure 4: Average APCEI score of implanted patients according to the duration of the cochlear implant use.

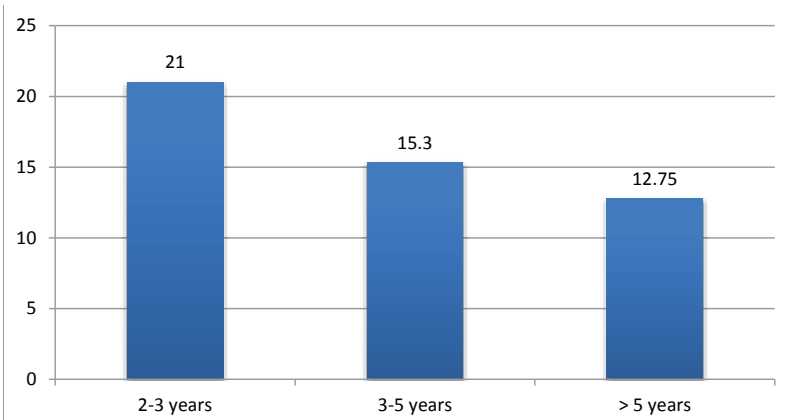

Figure 5: Average APCEl score by age of implantation.

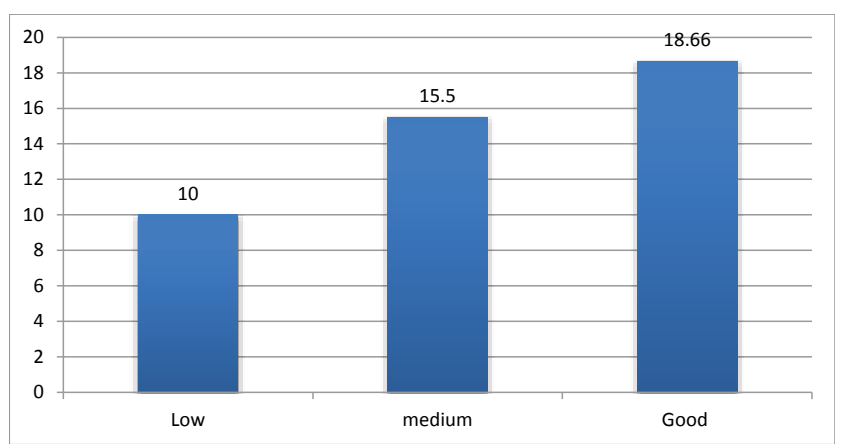

Figure 6: Average APCEl score in relation to parental investment and follow-up of speech therapy.

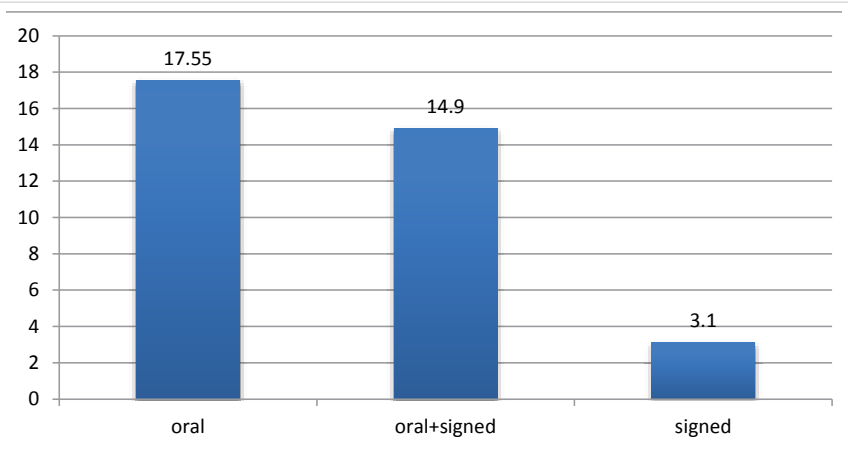

Figure 7: Average APCEI score according to the mode of communication

\section{Discussion}

Severe to profound hearing loss affects 1 of 1000 newborn each year. Recent studies show that this incidence could reach 2-3 births on thousand [2] .It is one of the major disabilities that adversely affect the development of speech and cognitive abilities in children.

Cls work by substituting the sensory hair cells within the cochlea with electrodes that stimulate electrically the auditory nerve fibers [3].

Pediatric CI candidates are in the majority of cases prelingual deafened children, who are born with SNHL due to genetic mutations, perinatal environmental exposures, or unidentified (idiopathic) causes. According to Nicholas et al. [1] these patients often obtain good speech outcomes after implantation with the best results, occurring when implanted within 1 to 2 years of age [1]. Table 2 provides a broad overview of conventional CI indications [3].

The FDA requires children to be 12 months of age. However several centers in the U.S. and Europe are implanting children as young as 6 months old [5]. Colletti and et al. [6] reported on 12 children implanted at or before the age of 6 months; four years after implantation, these children had receptive and expressive language skills similar to normal-hearing peers. However, Tajudeen and et al. [4], did not confirm clear evidence of improved outcomes in children implanted in the first year of life compared with those im- planted a year later [4]. 
Table 2: Cochlear implant candidacy guidelines

\begin{tabular}{|l|c|c|c}
\hline Children (12-24mo) & Children (2-17Y) \\
\hline Woring threshold recognition & $\begin{array}{c}\text { Moderate to profound SNHL in both ears }(>40 \mathrm{~dB}) \\
\text { recognition in the ear to be implanted (or } 40 \% \text { by CMS criteria) and } 60 \% \text { in } \\
\text { the contralateral ear or binaurally. }\end{array}$ & $\begin{array}{c}\text { Severe to profound SNHL }(>70 \mathrm{~dB}) \\
\text { defined by } 20-30 \% \text { word recognition } \\
\text { scores. }\end{array}$ & $\begin{array}{c}\text { Limited benefit from binaural } \\
\text { amplification trial based on the } \\
\text { MAIS. }\end{array}$ \\
\hline Abbreviations: CMS, centers for medicare and medicaid services; dB, decibels; SNHL, sensor neural hearing loss; MAIS, meaningful auditory integration scale
\end{tabular}

There has been an expansion in CI candidacy criteria. For example, children with auditory neuropathy spectrum disorder (ANSD) have shown to achieve reliable open-set speech recognition and the majority of patients with cochlear malformations (e.g. Mondini deformity), who were previously not implant candidates are now being implanted safely [7].

Cochlear implant candidacy has been extended also to some children with significant residual hearing [8]. An example is a bilateral and asymmetric SNHL, in which significant benefit can derive from cochlear implantation in the worse hearing ear in combination with a hearing aid in the better ear [9].

In addition, there is growing interest in implanting patients with single-sided deafness (SSD). At present time, implantation for SSD is not currently FDA approved, but increasing evidence suggests that this may be a viable option in the future [10].

Before implantation several factors must be considered to establish whether a child is suitable or not; thus, for a successful cochlear implantation the patient selection is of outstanding importance. A complete evaluation should comprise a series of tests, including audiologic, medical and imaging studies, as well as speech and language evaluation; furthermore, patient/ family counseling is fundamental to explain them the potential benefits and to create realistic expectations $[1,3]$.

Contraindications to implantation, such as complete labyrinthine aplasia, cochlear aplasia, cochlear nerve aplasia, and complete cochlear ossification should be eliminated by radiographic assessment. According to Parry et al. [11], magnetic resonance imaging (MRI) is the best modality for confirming a fluid-filled cochlear duct to receive the electrode, as well as the presence of a cochlear nerve to carry the signal to the brainstem and auditory cortex. Importantly, in older patients, obtaining an MRI prior to CI provides them with their last opportunity to obtain a high-quality brain image without artifact or the need to remove a magnet [11]. High resolution computed tomography (HRCT) also has utility, particularly for surgical planning in cochlear malformations, and can also be done in a faster, more cost effective manner compared with MRI [12].

Cochlear implantation is usually performed under general anesthesia without muscle relaxation to allow for facial nerve monitoring. Selected elderly patients have also been safely implanted under conscious sedation [13]. Patients should be preoperatively vaccinated according to Centers for Disease Control and Prevention (CDC) guidelines for meningitis prophylaxis [14]. CIs are placed through small skin incision in the retroauricolar region; a surgical opening is made in the mastoid to provide access to the cochlea from behind. Once identified the round window, the latter is opened and the electrode array is inserted into the cochlea. After the implant has been secured in place and before closing the surgical access, intraoperative electrophysiological testing is performed to verify the correct functioning of the device and to record the neural responses to the electrical stimuli. In standard cases, the procedure takes about 2 hours; children are generally discharged from hospital within $2-3$ days $[1,3]$.

Cochlear implantation has a low rate (about 10\%) of complications; major complications are rare, accounting for only 20 to $30 \%$ of all complications on average [15], and include facial nerve injury $(0.39 \%)$, perilymphatic gusher/ cerebrospinal fluid fistula $(0.25 \%)$, and meningitis $(0.11 \%)$. The most frequent complications are temporary taste disturbance, wound infections, and device failure $[3,16]$.

The activation of the implant is usually done $2-4$ weeks after surgery, when healing is complete, and consists in setting the sound levels presented to each electrode within the cochlea. During the first year after activation, the cochlear implant is periodically tuned according to the child responses in order to maintain optimal stimulation levels [3].

There are remarquable results regarding the acquisition of spoken language in implanted children with profound deafness. Prelingually deaf children develop significant speech perception and production abilities over time. According to O'Donoghue et al. 1998 [16], these achievements may appear limited in the first two years, but show significant improvement after the second year of implantation, and do not reach a plateau, even 5 years following implantation.

Prelingually deaf children also develop significant speech intelligibility, but a long period of cochlear implant use is needed prior to the emergence of intelligible speech [17].

Nevertheless, children with CI show an important variability. According to Gerard et al. and Clark et al. [18,19], several factors, such as the aetiology of deafness, the age of the child at the time of the $\mathrm{CI}$, the presence of residual hearing, the process of the auditory rehabilitation, the family participation in the therapeutic process, all may influence the final performance.

The protocols of evaluation in post-implantation are multiple [17-18], varying from one center and one country to another (TEEP, MUSS, APCEI, CAP, MAIS, SIR.). There is no 
standardized protocol adapted to our culture. Despite being subjective, the APCEI scale was chosen in our evaluation but it remains a simple test, quick to perform and explores the different areas of speech assessment.

\section{Conclusion}

Cochlear implantation is worldwide considered a safe and highly effective technique in rehabilitating children with severe to profound SNHL. Its effectiveness has already been demonstrated and our results are in agreement with those of the literature. Its Benefits include not only better abilities to hear and to develop speech and language skills, but also improved academic attainment, improved quality of life, and better employment status.

\section{References}

1. Nicholas $L$, Deep Eric M, Jethanamest D, Matthew L. Carlson: Cochlear Implantation: An Overview. J Neurol Surg B Skull Base. 2019;80:169-177. PubMed: https://www.ncbi.nlm.nih.gov/pubmed/30931225

2. Centers for Disease Control and Prevention. National Center on Birth Defects and Developmental Disabilities. Hearing loss. 1999.

3. Vincenzo V, Bacciu A, Guida M, Marra F, Bertoldi B, et al. Pediatric cochlear implantation: an update. Ital J Pediatr. 2014; 40: 72. PubMed: https://www.ncbi.nlm.nih.gov/pubmed/25179127

4. Tajudeen BA, Waltzman SB, Jethanamest D, Svirsky MA. Speech perception in congenitally deaf children receiving cochlear implants in the first year of life. Otol Neurotol. 2010; 31: 1254-1260. PubMed: https://www.ncbi.nlm.nih.gov/pubmed/20814343

5. Holman MA, Carlson ML, Driscoll CL, Grim KJ, Petersson RS, et al. Cochlear implantation in children 12 months of age and younger. Otol Neurotol. 2013; 34: 251-258.

PubMed: https://www.ncbi.nlm.nih.gov/pubmed/23444471

6. Colletti L, Mandalà M, Colletti V. Cochlear implants in children younger than 6 months. Otolaryngol Head Neck Surg. 2012; 147: 139-146. PubMed: https://www.ncbi.nlm.nih.gov/pubmed/22454156

7. Tucci DL, Telian SA, Zimmerman-Phillips S, Zwolan TA, Kileny PR Cochlear implantation in patients with cochlear malformations. Arch Otolaryngol Head Neck Surg. 1995; 121: 833-838.

8. Mondain M, Sillon M, Vieu A, Levi A, Reuillard-Artieres F, et al. Cochlear implantation in prelingually deafened children with residual hearing. Int J Pediatr Otorhinolaryngol. 2002; 63: 91-97.
PubMed: https://www.ncbi.nlm.nih.gov/pubmed/11955600

9. Dowell RC, Hollow R, Winton E. Outcomes for cochlear implant users with significant residual hearing. Arch Otolaryngol Head Neck Surg. 2004; 130: 575-581.

PubMed: https://www.ncbi.nlm.nih.gov/pubmed/15148179

10. Hansen MR, GantzBJ, DunnC. Outcomes after cochlear implantation for patients with single-sided deafness, including those with recalcitrant Ménière's disease. Otol Neurotol. 2013; 34: 1681-1687. PubMed: https://www.ncbi.nlm.nih.gov/pubmed/24232066

11. Parry DA, Booth T, Roland PS. Advantages of magnetic resonance imaging over computed tomography in preoperative evaluation of pediatric cochlear implant candidates. Otol Neurotol. 2005; 26: 976982. PubMed: https://www.ncbi.nlm.nih.gov/pubmed/16151346

12. Ellul S, Shelton C, Davidson HC, Harnsberger HR. Preoperative cochlear implant imaging: is magnetic resonance imaging enough? Am J Otol. 2000; 21: 528-533.

13. Shabashev S, Fouad Y, Huncke TK, Roland JT. Cochlear implantation under conscious sedation with local anesthesia; safety, efficacy, costs, and satisfaction. Cochlear Implants Int. 2017; 18: 297-303. PubMed: https://www.ncbi.nlm.nih.gov/pubmed/28934019

14. Reefhuis J, Honein MA, Whitney CG, Chamany S, Mann EA, et al. Risk of bacterial meningitis in children with cochlear implants. N Engl J Med. 2003; 349: 435-445.

PubMed: https://www.ncbi.nlm.nih.gov/pubmed/12890842

15. Heman-Ackah SE, Roland JT Jr, Haynes DS, Waltzman SB. Pediatric cochlear implantation: candidacy evaluation, medical and surgical considerations and expanding criteria. Otolaryngol Clin N Am. 2012; 45: 41-67.

PubMed: https://www.ncbi.nlm.nih.gov/pubmed/22115681

16. O'DonoghueGM,NikolopoulosTP,ArchboldSM,TaitM.Speechperception in children after cochlear implantation. Am J Otol. 1998; 19: 762-767. PubMed: https://www.ncbi.nlm.nih.gov/pubmed/9831151

17. Allen MC, Nikolopoulos TP, O'Donoghue GM. Speech intelligibility in children after cochlear implantation. Am J Otol. 1998; 19: 742-746.

18. Gérard JM, Deggouj N, Hupin C, Buisson AL, Monteyne V, et al. Evolution of communication abilities after cochlear implantation in prelingually deaf children. Int J Pediatr Otorhinolaryngol. 2010; 74: 642-648. PubMed: https://www.ncbi.nlm.nih.gov/pubmed/20347162

19. Clark JH, Aggarwal $P$, Wang NY, Robinson R, Niparko JK, et al Measuring communicative performance with the FAPCl instrument: preliminary results from normal hearing and cochlear implanted children. Int J Pediatr Otorhinolaryngol. 2011; 75: 549-553. PubMed: https://www.ncbi.nlm.nih.gov/pubmed/21296432 